\title{
Konsep Musikal Instrumen Kendang dalam Gamelan Gong Kebyar
}

\author{
I Putu Danika Pryatna ${ }^{1}$ dan Hendra Santosa \\ 1 Program Studi Seni Pascasarjana, Institut Seni Indonesia Denpasar \\ ${ }^{2}$ Program Studi Seni Karawitan, Institut Seni Indonesia Denpasar
}

\begin{abstract}
Musical Concept of Kendang Instrument in Gamelan Gong Kebyar. Holding a Balinese tamer role in a barong gamelan kebyar was not as simple as it seems. Being a controller in a gamelan gong kebyar in Bali, must have a soul of leadership so that a school can show a good performance. Not all Balinese people have such a soul because not all Balinese performers are diligent in training themselves to have useful musical techniques and sensitivity. The researcher wants to know the concept of a person in charge of leading a gamelan gong kebyar in Bali. This research uses the descriptive qualitative method, which uses observation, interviews, literature studies, and documentation techniques. The results found in this study are the musical concept of a Balinese tamer in leading a Balinese gong kebyar of gamelan performance. This musicality concept includes playing the drum, adjusting the dynamics of the song, adjusting the tempo, and starting the gending and ending the gending. In practice, musicality is implemented through body language, drum patterns, and loud sounds. The idea of musicality is fundamental owned by a Balinese performer, so that performance becomes better and neater to amaze the audience.
\end{abstract}

Keywords: concept; musicality; Balinese drummers

\begin{abstract}
ABSTRAK
Memegang peranan sebagai seorang pengendang Bali di dalam sebuah barungan gamelan gong kebyar, ternyata tidak sesederhana yang terlihat. Menjadi seorang pengendang di dalam sebuah sekeha gamelan gong kebyar Bali, harus memiliki jiwa kepemimpinan, agar sebuah sekeha dapat menampilkan pertunjukan yang bagus. Tidak semua pengendang Bali memiliki jiwa seperti itu, itu dikarenakan tidak semua pengendang tekun dalam melatih dirinya agar memiliki teknik dan kepekaan musikal yang baik. Peneliti ingin mengetahui konsep seorang pengendang yang ada di dalam memimpin sebuah sekeha gamelan gong kebyar Bali. Penelitian ini menggunakan metode deskriptif kualitatif,yang dalam implementasinya menggunakan teknik observasi, wawancara, studi pustaka dan dokumentasi. Hasil yang ditemukan di dalam penelitian ini adalah konsep musikalitas seorang pengendang Bali di dalam memimpin sebuah pertunjukan gamelan gong kebyar Bali. Konsep musikalitas ini meliputi teknik bermain kendang, mengatur dinamika lagu, mengatur tempo, memulai gending dan mengakhiri gending. Dalam praktikalnya konsep musikalitas ini di implementasikan melalui bahasa tubuh, pola kendang dan keras lirihnya suara kendang. Konsep musikalitas ini sangat penting dimiliki oleh seorang pengendang Bali, agar sebuah pertunjukan menjadi lebih bagus dan rapi, sehingga dapat memukau penonton.
\end{abstract}

Kata kunci: konsep; musikalitas; pengendang Bali

\section{Pendahuluan}

Jika mendengarkan musik yang sesuai dengan selera, seseorang akan mengikuti aliran musik yang sedang dinikmatinya. Hal ini terjadi karena musik adalah sebuah peristiwa yang mengalir begitu saja. Seperti yang dinyatakan oleh Daryana dan Murwaningrum, masyarakat modern sangat sadar

\footnotetext{
Alamat korespondensi: Program Studi Seni Pascasarjana, ISI Denpasar, Jalan Nusa Indah Denpasar Bali.
} E-mail: putudanika@gmail.com; HP.: 089676157265. 
bahwa musik merupakan sebuah peristiwa yang mengalir begitu saja, dengan melewati batas ruang dan waktu, musik dapat mendefinisikan dirinya sendiri tanpa bantuan dari seni lainnya (Daryana \& Murwaningrum, 2019). Musik memiliki berbagai macam aliran dan jenis. Pada umumnya, musik dapat digolongkan menjadi dua jenis, yaitu musik tradisional dan musik modern. Musik tradisional adalah sebuah musik yang diwariskan secara turuntemurun dan tetap mempertahankan bentuk, fungsi, dan makna dari instrumen musik tersebut.

Kendang adalah salah satu instrumen karawitan Bali yang masuk dalam golongan perkusi. Pada umumnya, kendang Bali dibuat dari bahan kayu yang dibentuk sedemikian rupa dan dilapisi selaput (kulit sapi) di setiap sisinya. Seperti yang dikatakan oleh I Made Bandem, kendang itu dibuat dari bahan kayu nangka, jati, atau seseh (batang kelapa) yang dibentuk seperti lingkaran memanjang. Setelah dibentuk, kendang dibungkus dengan kulit sapi di kedua sisinya, lalu kendang dikencangkan dengan tali yang dibuat dari kulit sapi, atau yang di Bali biasanya disebut dengan jangat (Bandem, 2013). Instrumen kendang di Bali sudah tersurat dalam berbagai prasasti mulai dari zaman Dinasti Warmadewa dengan sebutan padaha (Santosa, 2017). Selain itu, instrumen kendang diperkirakan sudah ada sejak zaman dahulu. Keberadaannya tersebar di seluruh pulau yang ada di Indonesia. Seperti pernyataan I Wayan Suweca, jika dilihat dari sejarah perkembangannya, instrumen kendang sudah sangat banyak tersebar di kepulauan Indonesia. Pulau-pulau tersebut ialah Sumatra, Jawa, Sulawesi, Kalimantan, Bali, dan Nusa Tenggara. Ada pendapat yang mengatakan bahwa instrumen kendang sudah ada sejak zaman dahulu kala. Pada mulanya, diperkirakan instrumen kendang hanya memiliki muka satu dan kemudian dalam perkembangannya menjadi kendang yang memiliki muka dua (Suweca, 2005).

Jika dilihat dari ilmu organologinya, instrumen kendang memiliki bentuk yang sangat unik. Namun di balik keunikan bentukya tersebut, kendang memiliki banyak sekali ilmu di luar konteks organologinya. Teknik, pola, dan konsep musikalitas adalah salah satu contoh kecil ilmu yang ada di dalam instrumen kendang Bali. Hal ini menunjukan bahwa kegiatan untuk mempelajari sebuah ilmu organologi tidak hanya terbatas melalui bentuk saja, melainkan juga meliputi konteks di luar ilmu organologi tersebut. Seperti yang dinyatakan oleh Ediwar, Minawati, dan Yulika, organologi sebagai ilmu tentang instrumen musik seharusnya tidak hanya mencakup sejarah dan deskripsi instrumen saja, tetapi juga mendalami aspek ilmu instrumen musik, seperti teknik-teknik permainan instrumen, fungsi secara musikalitas, hiasan atau ornamentasi (yang dibedakan dengan konstruksi), dan berbagai pendekatan sosial budaya yang ada kaitannya dengan instrumen tersebut (Ediwar, Minawati, Yulika, 2019).

Ada berbagai macam jenis kendang yang ada di Pulau Bali, jika digolongkan secara umum dari segi ukurannya dapat dibagi menjadi empat jenis, yaitu: kendang sangat besar, kendang besar, kendang menengah dan kendang kecil. Kendang yang termasuk dalam golongan sangat besar ialah, kendang mebarung dari Kabupaten Jembrana, dari golongan kendang besar ialah kendang lelambatan dan kendang beleganjur, dari golongan kendang menengah ialah kendang gupekan dan kendang bebarongan, dan yang terakhir dari golongan kendang kecil ialah, kendang angklung dan kendang krumpungan. Selain membahas instrumen kendang tersebut, jika ingin mempelajari kendang Bali, karakter pengendang Bali juga perlu dipelajari.

Pada zaman dahulu, instrumen kendang digunakan sebagai media untuk menyemangati prajurit yang akan bertempur dalam medan peperangan. Setelah berakhirnya zaman peperangan, muncullah sebuah kesenian dalam bentuk barungan gamelan yang termasuk dalam jenis gamelan golongan tua. Gamelan golongan tua adalah gamelan yang muncul pertama kali dan tidak menggunakan instrumen kendang dalam barungan-nya. Instrumen kendang mulai digunakan sejak munculnya gamelan golongan madya dan baru. Namun, instrumen kendang mulai menonjol perannya sebagai instrumen utama di dalam gamelan golongan baru, yaitu gamelan gong kebyar. Gamelan gong kebyar yang termasuk jenis gamelan golongan baru merupakan perkembangan dari jenis gamelan golongan madya yang belum sepenuhnya memberikan peran pemimpin bagi 
seorang pengendang. Lain halnya dengan gamelan gong kebyar yang sudah menonjolkan peran pengendang-nya pada segi musikalitasnya. Seperti yang dikatakan oleh Bandem, bahwa gamelan golongan baru merupakan jenis gamelan yang perkembangannya lebih maju dari gamelan golongan madya. Selain instrumentasinya yang lebih banyak dan lebih lengkap, komposisi lagunya pun lebih kompleks dan lebih canggih. Teknik permainannya dikembangkan sedemikian rumit sehingga mampu memberikan peluang kepada senimannya untuk mengekspresikan ciptaannya sebebas-bebasnya. Pada gamelan golongan baru ini, peranan instrumen kendang dan juru kendang jauh lebih menonjol daripada kelompok sebelumnya, dan fungsinya juga masih sebagai pemimpin dan pemurba irama (Bandem, 2013). Tidak hanya di Bali, peneliti juga menemukan fungsi kendang sebagai pemimpin pada gamelan Jawa. Seperti yang diungkapkan oleh Bambang Sri Atmojo, kendang adalah sebuah instrument musik yang ada di dalam ensambel gamelan Jawa, dan instrument ini mempunyai peranan yang sangat penting. Peranan ini dapat diketahui bahwa kendang selalau hadir dalam sajian uyon-uyon, iringan tari, iringan pakelir, dan iringan kethoprak dengan peran utamanya sebagai pemurba irama, yaitu bertugas menguasai jalannya irama dalam sebuah gending, menentukan tempo, serta memulai ataupun menghentikan penyajian dalam sebuah pertunjukan seni (Atmojo, 2010).

Gamelan gong kebyar menjadikan instrumen kendang sebagai pemimpin dalam konteks musikalitasnya. Pada gamelan golongan madya peranan instrumen kendang sudah mulai berfungsi sebagai pimpinan dalam konteks musikalitas dari sebuah barungan gamelan Bali. Selain itu, kendang juga sudah memiliki peranan penting sebagai pemimpin dan pengatur jalannya sebuah gending atau lagu yang disebut dengan istilah pamurba irama (I Gede Made Indra Sadguna, 2010).

Seorang pengendang Bali memiliki posisi yang vital di dalam sebuah barungan gamelan gong kebyar. Posisi sebagai pemimpin harus diambil oleh seorang pengendang Bali. Jika seorang pengendang Bali tidak memiliki jiwa pemimpinan, ia tidak akan memiliki wibawa dan kharisma dalam memimpin sebuah sekeha gamelan gong kebyar. Wibawa dan kharisma ini sangat penting dimiliki oleh seorang pengendang Bali. Wibawa dan kharisma tersebut mampu menghipnotis penonton dan anggota sekeha gong lainnya, agar mau menuruti hal yang dikatakan dan dikehendaki olehnya. Wibawa dan kharisma itu dapat diraih seorang pengendang Bali dengan cara tekun latihan sehingga memiliki teknik bermain yang bagus, sopan-santun dalam bersikap, memiliki keberanian jika dalam posisi benar; dan berlapang dada jika dalam posisi kalah dan salah. Jika semua prinsip ini dilakukan oleh seorang pengendang Bali, ia akan memiliki ilmu, wibawa, dan kharisma yang lebih dari anggota sekehe gong lainnya. Jika seorang pengendang Bali sudah memiliki ilmu, wibawa, dan kharisma yang lebih dari anggota sekehe lainnya, sifat-sifat itu akan membuatnya lebih percaya diri di dalam memimpin anggota sekehe gongnya. Seorang pengendang Bali biasanya akan menjadi musisi yang paling menguasai lagu atau gending dan biasanya akan disebut guru oleh teman-temannya. Pandangan ini sejalan dengan yang dikatakan oleh Tenzer, "drumers are skilled musicians and usually teacher, who know all of the parts that are played by other instrumens in the ensemble" (Tenzer, 1998). Hal tersebut menunjukkan bahwa kriteria seorang pemimpin harus mengetahui hal-hal yang harus dilakukan oleh semua anggotanya, sehingga anggotanya tidak kehilangan arah dan tujuan pada saat melakukan sebuah pekerjaan.

Jika seorang pengendang Bali sudah memiliki wibawa dan kharismanya, ia akan lebih mudah dalam menjalankan fungsi dirinya sendiri dalam sebuah sekehe gamelan gong kebyar. Fungsi mendasar dari seorang pengendang Bali adalah sebagai pemurba irama, mengatur cepat lambatnya sebuah gending, mengatur dinamika (keras halusnya sebuah gending), memberi sinyal mulai dan berakhirnya sebuah gending dan masih banyak lagi yang lainnya. Banyaknya fungsi dan hal-hal yang menyangkut wibawa dari seorang pengendang Bali menunjukkan pentingnya posisi dan fungsi dari seorang pengendang Bali. Mengacu pada pentingnya posisi dan fungsi pengendang Bali, perlu diketahui pula tata cara menjadi seorang pengendang di dalam sebuah sekeha gamelan gong kebyar.

Seorang pengendang biasanya memimpin permulaan sebuah lagu atau gending sampai dengan 
mengakhirinya. Permainan instrumen kendang berfungsi untuk memimpin dalam sajian karawitan, fungsinya adalah untuk memulai gending, mempercepat, dan memperlambat tempo. Selain itu, fungsi kendang mengalihkan dari gending yang satu ke gending yang lainnya, serta memberikan jiwa pada gending agar gending menjadi lebih hidup dan memiliki taksu (Supanggah, 2009). Selain itu, seorang pengendang Bali juga sangat mahir di dalam mempengaruhi anggota sekehe gong yang lain agar mau menuruti perintahnya, dan menjadikan ia pemimpin yang dihormati. Kata 'mempengaruhi' ini sangat sejalan dengan arti sebuah kepemimpinan. Bertolak dari fenomena tersebut, fokus dari penelitian ini adalah untuk mengetahui konsep kepemimpinan yang dimiliki oleh seorang pengendang Bali di dalam sebuah sekehe gamelan gong kebyar. Dengan demikian, dapat diketahui filosofi kepemimpinan seorang pengendang Bali di di sebuah grup gamelan gong kebyar. Dengan informasi mengenai konsep kepemimpinan seorang pengendang Bali di dalam sebuah sekehe gamelan gong kebyar ini, minat generasi muda akan mampu ditumbuhkembangkan dalam mempelajari karawitan Bali, khususnya kendang Bali.

\section{Metode Penelitian}

Artikel ini merupakan hasil dari sebuah penelitian yang berjudul Konsep Musikalitas Seorang Pengendang Dalam Gamelan Gong Kebyar Bali. Salah satu sub atau bagian isi dari penelitian ini adalah konsep musikalitas seorang pengendang dalam memimpin sebuah grup gamelan gong kebyar Bali, dengan studi kasus seorang pengendang Bali. Metode yang digunakan untuk mengkaji konsep musikalitas seorang pengendang dalam memimpin sebuah grup gamelan gong kebyar Bali dalam artikel ini adalah metode deskriptif kualitatif. Implementasi dari penggunaan metode tersebut menggunakan teknik observasi, wawancara, dokumentasi, dan studi pustaka. Teknik observasi dilakukan dengan cara mengamati secara langsung tingkah laku seorang pengendang di dalam sebuah pertunjukan gamelan gong kebyar Bali, teknik wawancara dilakukan dengan mewawancarai seniman karawitan Bali yang berprofesi sebagai seorang pengendang, teknik dokumentasi dilakukan dengan cara merekam dan memfoto proses latihan seorang pengendang Bali termasuk pada saat memimpin sebuah group gamelan gong kebyar dari segi musikalitasnya, dan yang terakhir teknik studi pustaka dilakukan dengan cara mencari jurnal, buku, dan textbook dari hasil-hasil penelitian yang sejenis sehingga mampu menambah wawasan peneliti dan sekaligus dapat mengembangkan penelitian ini agar menjadi lebih sempurna.

Data yang dijabarkan dalam penelitian ini diperoleh melalui wawancara intensif dengan dua tokoh seniman karawitan Bali. Kedua tokoh tersebut ialah I Kadek Suryantara Asmara Putra dan I Ketut Suarjana. Beberapa kriteria ditetapkan untuk menentukan pemilihan informan. Dalam hal ini, informan merupakan seniman karawitan Bali yang berkomitmen menjadi pengendang dan pemimpin di dalam sanggar seninya. Untuk kategori pengendang yang memiliki jiwa kepemimpinan yang hebat, setidaknya seniman yang bersangkutan memiliki dua kriteria utama, yaitu: 1) pengalaman 3-5 tahun dalam bermain kendang Bali, baik dalam even perlombaan maupun tidak :2) menjadi ketua dalam sebuah sanggar seni dalam kurun waktu 2 tahun dan sekaligus mampu membuat sanggar tersebut semakin berkembang dan berprestasi dalam bidang seni. Penetapan kriteria ini dilakukan peneliti untuk mendapatkan data yang valid dan benar. Pembatasan informasi dari narasumber seniman karawitan Bali yang berkompeten dan berkomitmen dalam kariernya dilakukan agar bobot informasi yang disampaikan benar dan dapat dipertanggungjawabkan.

Artikel ini menggunakan model penelitian kualitatif, yang dalam penyajian hasil datanya diuraikan dengan bentuk deskriptif berupa katakata tertulis maupun lisan, seperti yang dinyatakan oleh Basrowi dan Suwandi. Adapun penelitian kualitatif yang dimaksud merupakan sebuah prosedur penelitian yang menghasilkan data deskriptif berupa kata-kata tertulis atau lisan dari orang-orang dan perilaku yang diamati (Basrowi dan Suwandi, 2008).

Teknik dari metode ini menghasilkan data yang bersifat deskriptif kualitatif. Jenis data yang 
bersifat kualitatif ini dianalisis dengan teori kepemimpinan yang menyebutkan bahwa sebagai suatu tindakan atau upaya untuk memotivasi atau mempengaruhi orang lain, maka teori ini dipergunakan peneliti untuk mengupas konsep musikalitas seorang juru kedang dalam memimpin sebuah grup gamelan gong kebyar Bali.

Persiapan sebelum wawancara dilakukan setidaknya selama satu minggu. Beberapa hal yang menjadi target informasi yang harus digali ialah keseluruhan proses kehidupan narasumber dari masa kanak-kanak hingga masa kini dalam menjalani kegiatan berkesenian, khususnya seni karawitan Bali. Kedua narasumber kemudian menunjukan cara memimpin sebuah sanggar seni karawitan dari segi musikalitasnya, dan sekaligus menelusuri pengalaman dalam belajar dan mengajar seni bermain kendang Bali. Sepanjang proses wawancara berlangsung, kedua narasumber membahas karakteristik dan kharisma dari seorang pengendang Bali dalam memimpin sanggar seninya. Proses wawancara berlangsung selama 60 sampai dengan 90 menit. Informasi dari narasumber direkam dan disalin dengan cermat dan seksama.

\section{Hasil dan Pembahasan}

Gamelan gong kebyar merupakan jenis gamelan golongan baru dan paling umum keberadaannya di Bali dewasa ini. Secara bentuk fisik gamelan gong kebyar merupakan penyederhanaan dari gamelan gong gede dengan pengurangan beberapa buah instrumennya. Seperti yang dinyatakan oleh I Putu Surya Pratama Wardhana, gamelan gong kebyar merupakan perkembangan dari ensambel gamelan gong gede yang beberapa instrumennya dihilangkan (I Putu Surya Pratama Wardhana, I Gede Mahendra Darma Wiguna, 2015).

Gong kebyar pertama kali muncul pada tahun 1914 di Bali Utara. Terdapat hubungan yang erat antara Bali dengan dunia Barat pada Masa Penjajahan Belanda (1846-1945) sehingga pada tahun 1914, di Bali Utara, muncul sebuah gamelan gaya baru yang disebut gamelan Gong Kebyar (Bandem, 2013). Kata kebyar jika diartikan secara umum bermakna mengejutkan, merefleksikan jenis musik yang sangat dinamis, keras, cepat, dan sekaligus dimainkan dengan ekspresi penabuh atau musisinya yang lincah dan meluap-luap. Hal ini berbeda dengan jenis gamelan golongan tua dan jenis gamelan golongan madya yang mengutamakan struktur dan kemerduan lagu atau keindahan melodi, jenis gamelan golongan baru, seperti gamelan gong kebyar yang lebih cenderung menonjolkan permainan ritme yang kompleks. Selain itu, permainan gamelan gong kebyar disajikan melalui gerak-gerik penabuh atau musisi yang meluap-luap (Bandem, 2013).

Dari beberapa jenis gamelan yang ada di pulau Bali, yang paling eksis dewasa ini adalah gamelan gong kebyar. Pada umumnya gamelan gong kebyar terdiri dari beberapa instrumen melodis seperti, instrumen trompong, instrumen reyong, giying, instrumen gangsa, instrument kantil, instrumen jublag, instrumen rebab, dan instrumen suling. Selain instrumen melodis gamelan ini juga memiliki beberapa instrumen ritmis seperti instrumen kendang, kajar, dan instrumen ceng-ceng. Dan yang terakhir instrument pembentuk matra seperti instrumen jegogan, instrumen kemong, instrumen kempur, dan instrumen gong (Yasa, 2018)

Gamelan gong kebyar memiliki laras pelog. Jika ditinjau lebih luas ada dua laras pokok di dalam karawitan Bali yaitu laras pelog dan slendro. Selain di Bali karawitan Sunda juga memiliki banyak laras dalam instrument karawitannya. Seperti yang diungkapkan oleh Asep Saepudin, karawitan Sunda memiliki lima laras yang terapat di dalam berbagai jenis insrtumen musik karawitannya, laras tersebut yaitu, laras salendro, laras pelog, laras degung, laras madenda atau laras sorog, serta laras mataraman atau laras mandalungan (Saepudin, 2015).

Instrumen kendang yang ada di dalam barungan gamelan gong kebyar memiliki peran yang sangat menonjol. Peranan sebagai pemimpin menjadi sebuah hal yang wajib diambil oleh seorang pengendang Bali. Dalam memimpin sebuah barungan gamelan gong kebyar, seorang pengendang menggunakan komunikasi musikal. Komunikasi musikal ini memberikan kode kepada anggota lain agar memunculkan sebuah diskusi yang melancarkan sebuah pertunjukan kesenian.

Ketika dua orang sedang berdiskusi, akan terjadi sebuah proses penyampaian pesan dari 
satu orang ke orang lain. Penyampaian pesan oleh pemberi pesan akan bisa dipahami oleh komunikan jika kedua orang tersebut menggunakan bahasa yang sama dan saling mengerti satu sama lain. Terdapat dua jenis bahasa yang dapat digunakan oleh manusia untuk menyampaikan pesan, yaitu bahasa verbal dan bahasa nonverbal. Bahasa verbal adalah bahasa yang dalam implementasinya menggunakan bentuk lisan dan tulisan dalam menyampikan pesan, sedangkan bahasa nonverbal adalah bahasa yang dalam implementasinya mengunakan bentuk gerakan tubuh, gerakan tangan, gelengan kepala dan sebagainya. Seorang pengendang lebih cenderung menggunakan bahasa non-verbal dalam memimpin sebuah grup gamelan gong kebyar Bali dari segi musikalitasnya. Komunikasi nonverbal adalah komunikasi yang implementasinya menggunakan isyarat bukan kata-kata (Mulyana, 2010). Teknik yang bagus akan menghasilkan suara kendang yang tegas dan jelas, dan seorang pengendang sebaiknya menguasai teknik tersebut. agar seseorang mampu memunculkan sebuah suara kendang yang jelas, mereka harus melatih tangan mereka dengan menggunakan kendang yang kulitnya masih kaku. Seperti yang diungkapkan oleh Danika Pryatna, seorang guru kendang akan menyarankan agar murid-muridnya belajar memukul kendang yang kulitnya masih kaku, karena jika murid tersebut mampu memunculkan suara cung pada kulit kendang yang masih kaku, maka akan sangat mudah sekali memunculkan suara cung pada kulit kendang yang sudah lentur. Ibarat pepatah mengatakan bersakit-sakit dahulu bersenangsenang kemudian (Pryatna, 2019). Selain Danika Pryatna, Indra Sadguna juga menyebutkan mengenai hal-hal yang perlu disiapkan jika ingin menjadi juru kendang yang baik. Sadguna menyatakan, dalam sebuah pertunjukan Barong atau pun pertunjukan kesenian yang memerlukan permainan kendang tunggal, seorang juru kendang hendaknya mempersiapkan hal-hal yang penting sebelum pertunjukan dimulai. Hal penting tersebut dimulai dari pemilihan kendang yang suaranya bagus dan kulitnya lentur, penguasaan warna suara kendang, dan memiliki pengetahuan mengenai pola kendang tunggal yang baik (I Gde Made Indra Sadguna, 2019).
Seorang pengendang Bali diwajibkan memiliki teknik permaian yang tinggi sebab dalam permainannya, ia mempresentasikan vokabuler ritmis yang dimiliki serta improvisasi yang kuat. Selain memiliki teknik permainan yang tinggi, seorang pengendang Bali juga harus mampu menjadi seorang mediator. Mediator yang dimaksud adalah penyampai pesan antara penari dengan musisi gamelan Bali yang mendukungnya. Ketika penari membuat gerakan tertentu, seorang pengendang harus mengerti maksud dari gerakan penari tersebut. Pemahaman tersebut kemudian ditransformasikan dengan bahasa musikal dan disampikan kepada musisi yang lainya, sehingga terjadi komuniksi yang jelas antara penari, pengendang, dan musisi yang mendukungnya. Proses komunikasi seperti ini sangat berbeda dengan proses dari komunikasi verbal. Dalam komunikasi musikal, proses penyampaian pesannya menggunakan modus yang berbeda dengan komunikasi verbal, tetapi tidak berarti bahwa pengungkapan komunikasi jenis ini tidak mungkin dilakukan oleh manusia untuk kehidupan sehari-harinya (Santosa, 2008).

Peran pengendang Bali juga memerlukan konsep dan jiwa kepemimpinan di dalam dirinya sehingga dapat diterapkan untuk memimpin sebuah group gamelan gong kebyar Bali. Kemampuan memimpin sebuah group gamelan gong kebyar Bali dapat dilihat dari konsep musikalitasnya. Konsep kepemimpinan musikalitas dapat dilihat pada saat pementasan sebuah lagu atau gending.

\section{Konsep Musikal Pengendang dalam Memimpin Grup Gamelan Gong Kebyar}

Konsep musikalitas seorang pengendang dalam memimpin grup gamelan gong kebyar Bali diimplementasikan dengan cara mengatur dinamika atau keras lirihnya frekuensi suara dari instrumen kendang dalam sebuah komposisi lagu atau gending (Prakasih, 2018). Dinamika dalam sebuah permainan gending tersebut, meliputi keras lirih dan cepat lambatnya sebuah lagu. Fungsi pengendang dalam gamelan Bali adalah sebagai pemurba irama, mengatur dinamika lagu atau gending, dan juga termasuk mengatur cepat lambatnya tempo dan keras lirihnya dari sebuah 
lagu yang sedang dipertunjukan atau dimainkan (Bandem, 2013). Pengaturan dinamika dalam sebuah gending merupakan sebuah kegiatan yang tidak mudah dilakukan oleh pengendang pemula.

Saat seorang pengendang mengatur dinamika dalam sebuah komposisi gending karawitan Bali, ia harus hafal dengan jiwa gending tersebut. Jiwa yang dimaksud adalah dinamika, tempo, ritme dan lain-lain. Hal ini terkait dengan keberadaan dinamika sebagai penentu letak keras dan halusnya suara dari sebuah gending. Seorang pengendang Bali harus mampu memberi kode dan petunjuk kepada musisi dari instrumen gamelan yang lain mengenai letak keras dan halusnya sebuah komposisi gending karawitan Bali.

Selain itu, seorang pengendang Bali dituntut untuk mampu menguasai dan memberi petunjuk kepada musisi yang lain. I Made Bandem juga menyebutkan beberapa syarat untuk bisa menjadi pengendang Bali yang baik. Adapun persyaratannya sebagai berikut.

1. Secara fisik, mampu duduk dengan baik (masila nyempel) selama berjam-jam ketika sedang bermain kendang Bali.

2. Membuat bunyi kendang dengan jelas dan tegas, magagedig atau matatekep dan menguasai bunyi kendang dengan lengkap dan baik, dengan menggunakan panggul (stik pemukul) maupun telapak tangan. Pengendang harus mampu membunyikan kendang dengan baik yang akan menimbulkan nilai estetis tersendiri sehingga dapat dinikmati oleh pengendang dan juga pendengarnya.

3. Mengetahui gending (paniti giying, penyacah, calung, jegog), dan pamurba irama atau instrumen kolotomik (kajar, kempur, klentong, dan gong).

4. Menguasai pupuh kendang (hasta windu atau palet).

5. Mampu membuat improvisasi, hiasan-hiasan pola kendang, dan macingklak (keluar dari rhythm) di luar pupuh dari melodi gending atau lagu.

6. Mengetahui koreografi dan pembendaharaan gerak tari seperti pajalan (pajalan adeng, ngayal, malpal); angsel-angsel (angsel bawak, angsel lantang, dan angsel kado) (Bandem, 2013).
Dari penjelasan Bandem tentang syarat untuk bisa menjadi seorang pengendang Bali yang baik, kriteria pengendang adalah sebagai berikut. Pertama, mampu duduk selama berjam-jam dimaksudkan agar pengendang tidak meninggalkan tempat pementasan sehingga sebuah pementasan menjadi lebih sempurna kerena tidak ada satupun musisi gamelan yang meninggalkan panggung pementasan. Selain mampu duduk dengan lama, kecakapan seorang pengendang dalam membunyikan instrumen kendang mampu menambah wibawa di dalam diri seorang pengendang tersebut. Hal itu terbentuk karena bunyi kendang yang dimainkan dengan jelas, tegas, dan bagus akan menambah rasa kagum penonton kepada seorang pengendang.

Kedua, hafal dengan gending menjadi kriteria yang sangat penting bagi seorang pengendang Bali. Hal itu menjadi suatu keharusan karena jika seorang pengendang tidak hafal dengan gending atau lagu yang dimainkannya, permainan musisi dari instrumen lainnnya akan ikut hancur. Hal tersebut terjadi karena pemimpinnya tidak bisa memimpin alur sebuah gending dengan baik. Selain itu, seorang pengendang harus menguasai pola kendang yang

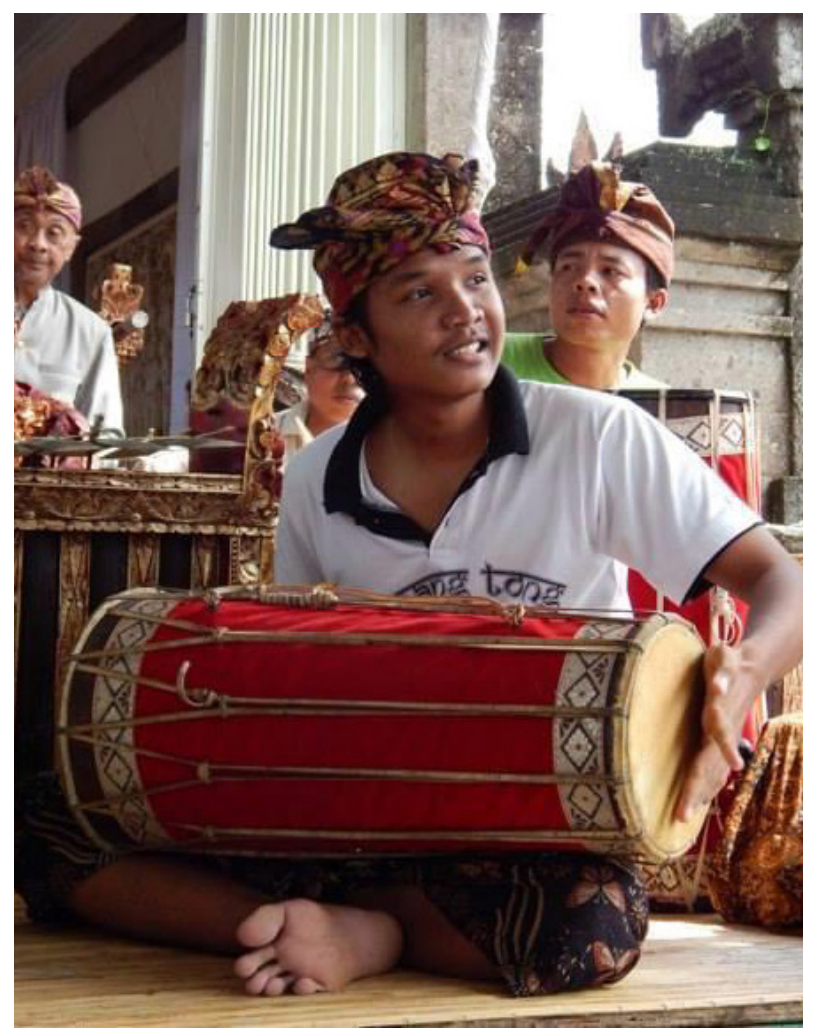

Gambar 1: Seorang pengendang Bali sedang memimpin sebuah grup gamelan gong kebyar Bali dari segi musikalitasnya. (Foto: Danika, 2013) 
akan dimainkan dalam sebuah gending karena setiap gending membutuhkan pola kendang yang berbedabeda. Perbedaan pola kendang itu ditentukan oleh gerakan penari yang direspon oleh pengendang melalui pola kendang yang sesuai. Dalam sebuah pementasan kesenian Bali sering terjadi hal yang tidak terduga. Seperti penari secara mendadak membuat gerakan improvisasi, pengendang juga harus siap dengan pola kendang improvisasi agar mampu mengimbangi gerakan penari yang dibuat secara mendadak tersebut. Oleh karena itu, seorang pengendang harus memiliki banyak pola kendang cadangan dan insting yang tajam dalam merespon gerakan improvisasi yang diberikan oleh penari. Memunculkan sebuah pola kendang dengan improvisasi, membutuhkan daya kreativitas yang tinggi dan instan. Daya kreativitas adalah sebuah daya cipta yang memunculkan ide-ide yang baru. Daya kreativitas jika diibaratkan ke dalam anatomi organ manusia, di ibaratkan seperti jantung. Itu dikarenakan kreativitas merupakan bagian yang terpenting di dalam sebuah proses penciptaan karya seni. Seperti yang diungkapkan oleh Prakasih, kreativitas merupakan element yang sangat penting dalam proses penciptaan sebuah komposisi karya seni, kreativitas di ibaratkan seperti jantung dalam proses penggarapan sebuah karya seni (Putu Paristha Prakasih, Hendra Santosa, 2018).

Selain itu, seorang juru kedang juga harus mengetahui gerak tari yang akan diiringinya agar koneksivitas antara pukulan kendang dan gerakan penari mengalami aksentuasi yang seimbang pada saat pementasan.

Seorang pengendang harus memiliki pukulan yang mantap jika ingin menyukseskan sebuah pertunjukan seni dengan grup gamelan yang dipimpinnya. Pukulan yang mantap dan bagus itu juga disebut dengan gegedig wayah. Kekendangan atau mekendang tunggal adalah permainan yang memerlukan keterampilan secara virtuistik berupa intensitas dan kualitas permainan yang mencerminkan suatu kematangan dengan stilisasi tertentu yang dalam istilah karawitan disebut "gegedig wayah". Virtuistik tersebut berupa kemampuan teknis yang dimiliki oleh seorang pengendang dalam memimpin sebuah group gamelan dari sisi musikalitasitasnya (Astita, 1998).
Jika seorang pengendang sudah memiliki gegedig yang wayah, sebuah pementasan seni akan berjalan lancar dan bagus. Hal itu dikarenakan oleh seorang pengendang yang diibaratkan sebagai jantungnya dari sebuah grup gamelan gong kebyar. Jika dikorelasikan ke dalam tubuh manusia, jantung menjadi hal yang paling penting. Jika jantung manusia tidak bekerja dengan baik, seluruh organ tubuh manusia tidak akan berfungsi dengan baik.

Seorang pengendang Bali harus memiliki jiwa pemimpin. Hal itu menjadi syarat mutlak karena hanya pengendang yang bisa mengatur jalannya sebuah gending atau lagu. Hal itu seperti yang dinyatakan oleh I Kadek Suryantara Asmara Putra.

"Pengendang itu harus mengetahui fungsi dari instrumen kendang tersebut, pengendang adalah seorang pemimpin yang bisa mengatur jalannya sebuah lagu, baik dari cepat lambat, keras lirih, yang disebut pemurba irama." (wawancara lewat media aplikasi whatsapp dengan I Kadek Suryantara Asmara Putra pada hari Minggu, 8 Desember 2019, diperbolehkan untuk dikutip).

Hal yang dikatakan oleh Kadek Suryantara Asmara Putra mengarah pada cara seorang pengendang Bali memimpin jalannya permainan sebuah gending dalam sebuah group gamelan gong kebyar Bali. Selain I Kadek Suryantara Asmara, I Ketut Suarjana juga memiliki pendapat bahwa seseorang yang berusaha selalu tekun menjadi seorang pengendang, akan memiliki jiwa pemimpin. Namun, tidak semua orang yang menjadi pengendang bisa memiliki jiwa tersebut. Hal itu bergantung pada niat seseorang tersebut. Jika dilihat dari sudut pandang karakter seorang pemain kendang, banyak pula pengendang yang tidak tegas dan tidak konsisten dalam memimpin sebuah grup gamelan Bali. Namun, ia memiliki kemampuan bermain kendang. Hal yang juga sering terjadi, kalau seseorang sudah bisa memainkan alunan pola kendang dengan baik, lama-kelamaan akan timbul jiwa seorang pemimpin, seperti memberi perintah akan dimulainya suatu musik atau gending (wawancara lewat media aplikasi whatsapp dengan I Ketut Suarjana pada hari Selasa, 24 Maret 2020, diperbolehkan untuk dikutip).

Jadi, menurut hasil wawancara dengan I Ketut Suarjana, tidak semua pengendang Bali memiliki 
jiwa pemimpin yang baik. Jika ingin memiliki jiwa tersebut, seorang pengendang harus memiliki niat yang kuat dalam mempelajari konsep musikalitas yang akan menjadikan ia sebagai pemurba irama dalam gamelan gong kebyar Bali.

\section{Implementasi Konsep Musikalitas Seorang Pengendang Bali dengan Menggunakan Bahasa Tubuh}

Konsep musikalitas seorang pengendang dalam memimpin sebuah grup gamelan gong kebyar Bali dapat diwujudkan melalui isyarat dari bahasa tubuh dan suara tertentu dari instrumen kendang yang memberikan sebuah isyarat. Ada beberapa macam bahasa tubuh yang dimiliki oleh seorang pengendang dalam sebuah pertunjukan gamelan gong kebyar Bali. Adapun beberapa bahasa tubuh dari seorang pengendang Bali adalah sebagai berikut.

1. Membungkuk sedikit dan kembali tegap dengan tiba-tiba.

Membungkuk sedikit dengan tiba-tiba memiliki arti bahwa melodi tertentu dalam sebuah gending harus dimainkan dengan frekuensi suara yang lebih lirih atau halus. Setelah pengendang membungkuk sedikit dan tiba-tiba kembali ke posisi semula dengan postur badan tegap, hal itu menandakan bahwa pemain dari instrumen lain harus memainkan melodi tertentu dalam sebuah gending dengan frekuensi suara yang lebih keras.

Dalam dunia tari Bali, gerakan yang direspon oleh seorang juru kedang ini disebut

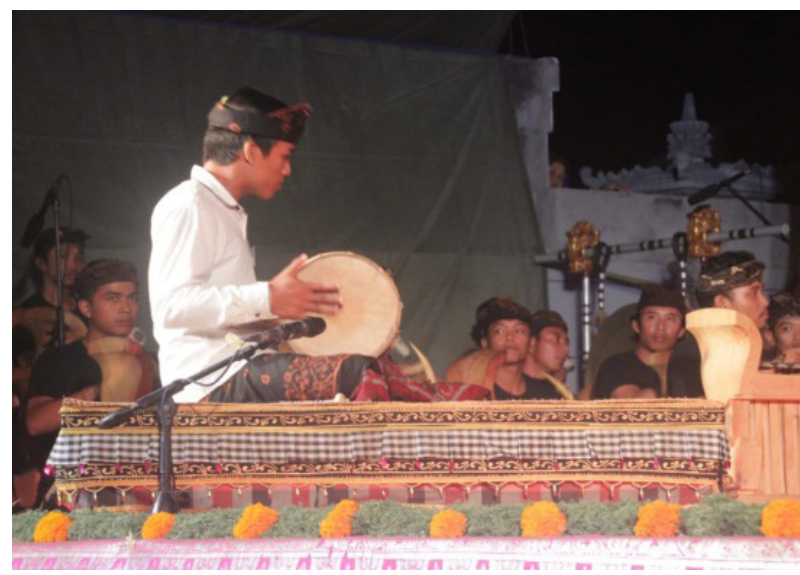

Gambar 2: Seorang pengendang Bali sedang memimpin sebuah grup gamelan gong kebyar Bali dengan bahasa tubuh membungkuk sedikit. (Foto: Danika, 2012) dengan gerakan malpal. Teknik malpal tersebut berupa gerakan seorang penari yang sedang berjalan, yang langkahnya jatuh sesuai dengan tempo. Oleh karena itu dibutuhkan pola kendang yang panjang. Malpal memiliki arti melihat seseorang yang sedang berjalan dan jalan memiliki arti pemalpal atau pemilpil juga sebuah motif berjalan yang langkahnya jatuh pada tiaptiap hitungan atau ketukan pada melodi tertentu di dalam sebuah gending (Bandem, 1983).

Hal ini dipertegas dengan hasil wawancara dengan seorang akademisi tari yang bernama I Made Rianta. Hasil wawancara menguraikan bahwa malpal dalam teknik tari Bali: Nike gerakan tari igel muani keras ane nuut kajar nike pak. Gerakan nike termasuk tandang. Tandang nike gerakan perpindahan uli satu posisi ke posisi lain nike (wawancara lewat media aplikasi whatsapp dengan I Made Rianta pada hari Jumat, 24 April 2020, diperbolehkan untuk dikutip).

Gerakan malpal adalah gerakan kaki tari laki-laki yang menirukan permainan dari instrumen kajar. Gerakan ini termasuk gerakan yang disebut dengan tandang. Tandang adalah perpindahan gerakan dari satu posisi ke posisi lainnya. Terkadang teknik malpal yang ditarikan oleh penari berisi gerakan naik dan gerakan turun yang gemulai sehingga seorang pengendang secara otomatis merespon gerakan naik dan turun tersebut dengan teknik dan pola permaian kendang yang keras dan halus. Pada saat penari melakukan teknik gerakan

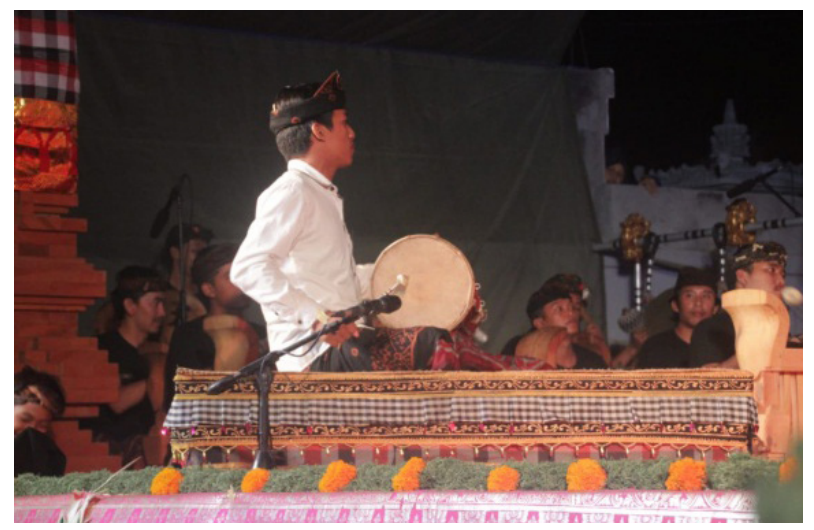

Gambar 3: Seorang pengendang Bali sedang memimpin sebuah grup gamelan gong kebyar Bali dengan bahasa tubuh kembali seperti semula dengan postur tubuh tegap. (Foto: Danika, 2012) 
malpal naik, pengendang akan meresponnya dengan teknik dan pola permaian kendang yang keras, sedangkan jika penari melakukan teknik gerakan malpal turun, seorang pengendang akan meresponnya dengan teknik dan pola permaian kendang yang lirih dan halus.

2. Memperkeras permainan pola kendang.

Selain memberi isyarat dengan bahasa tubuh, seorang pengendang juga bisa mengatur keras lirihnya melodi tertentu di dalam sebuah gending dengan bahasa musikal dari teknik dan pola permainan kendang-nya. Di saat seorang pengendang ingin memperkeras permainan instrumen dari pemain lain, ia akan memainkan kendang dengan keras. Demikian pula sebaliknya, jika seorang pengendang ingin memperhalus permainan instrumen dari pemain lain, seorang pengendang akan memainkan instrumen kendang dengan frekuensi yang lebih rendah dan halus.

Seorang pengendang Bali biasanya mulai memainkan instrumen kendang dengan keras pada saat akan memainkan pola angsel. Angsel adalah sebuah kode yang diberikan oleh seorang juru kedang kepada pemain dari insrumen lain dengan maksud mengubah dinamika pada melodi tertentu dalam sebuah gending atau lagu. Angsel adalah sebuah aba-aba untuk menandai perubahan dinamika pada melodi tertentu

$$
\begin{aligned}
& 0=\text { Nding } \quad+=\text { Kempur } \\
& \supset=\text { Ndong } \quad-=\text { Klentong } \\
& ?=\text { Ndeng } \quad(\quad)=\text { Gong } \\
& 0=\text { Ndung } \\
& v=\text { Ndang }
\end{aligned}
$$

Gambar 4: Notasi pola angsel. (Foto: Danika, 2020)

()

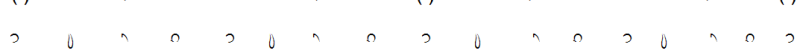

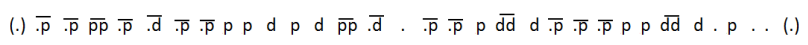
Gambar 5: Notasi pola angsel kendang Bali di dalam melodi gending Jauk Keras. (Foto: Danika, 2020)

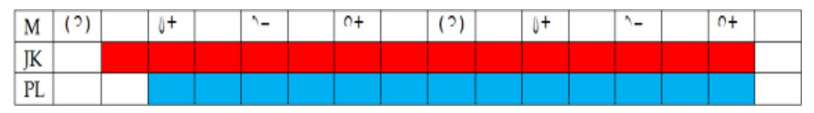

Gambar 6: Penempatan pola angsel kendang Bali di dalam gending Jauk Keras. (Foto: Danika, 2020) dalam sebuah gending (I Gede Made Indra Sadguna, 2010).

Untuk mempermudah dalam mengartikan pola angsel tersebut, dapat digambarkan dengan mengunakan notasi pada gambar 4 .

Arti dari simbol pada gambar no. 5 adalah implementasi dari permainan pola angsel kendang tunggal Bali dalam sebuah melodi dari gending Jauk Keras. Simbol "p" yang berbunyi pak dan simbol "d" yang berbunyi det dirangkai ke dalam bentuk notasi Bali.

Simbol "M" yang dimaksud pada gambar 6 adalah melodi, sedangkan simbol "JK" adalah juru kendang atau pengendang, dan simbol "PL" yang dimaksudkan adalah pemain lain. Melodi dari gending Jauk Keras digunakan sebagai contoh dalam menganalisis konsep musikalitas seorang pengendang Bali yang diimplementasikan melalui pola permainan angsel. Dalam memainkan angsel kendang, seorang pengendang akan memainkan instrumen kendangnya dengan keras sehingga tindakan tersebut memberi kode pada pemain yang lain agar memainkan instrumennya dengan keras pula. Warna merah dalam gambar 6 menunjukan seorang pengendang mulai memainkan angsel kendangnya setelah pukulan instrumen gong. Hal tersebut langsung diikuti oleh pemain lain yang diberi tanda dengan warna biru. Hal ini menunjukan pengendang memimpin melalui angsel kendang yang dimainkannya setelah gong pada nada ndong dibunyikan.

\section{Kesimpulan}

Konsep musikalitas seorang pengendang dalam barungan gamelan gong kebyar Bali adalah konsep seorang pengendang sebagai pemurba irama dalam sebuah gending atau lagu yang sedang dimainkan. Konsep musikalitas ini dapat dilihat pada saat seorang pengendang memainkan instrumen kendang Bali dalam sebuah pementasan seni seperti menjadi pemurba irama, mempercepat dan memperlambat tempo, mengatur dinamika, dan mengatur keras lirihnya sebuah gending pada saat pertunjukan berlangsung. Dalam implementasinya seorang pengendang memimpin sebuah grup gamelan gong 
kebyar Bali dengan menggunakan bahasa tubuh dan memperkeras frekuensi suara dari instrumen kendang-nya, sehingga hal tersebut dapat menjadi sebuah tanda yang akan memberikan informasi bagi pemain dari instrumen lainnya pada saat pementasan berlangsung.

Generasi muda dalam hal ini perlu turut melestarikan dan mulai mencintai kesenian tradisi, khususnya karawitan Bali. Jika ditelaah lebih dalam, karawitan Bali ternyata mengandung konsep-konsep yang menjadikan manusia tersebut memiliki nilai moral yang baik dan memiliki pedoman yang jelas dalam menjalani kehidupanya seperti konsep musikalitas yang ada di dalam diri seorang pengendang dalam memimpin sebuah grup gamelan gong kebyar Bali. Konsep musikalitas tersebut jika diterapkan dalam kehidupan seharihari, akan mampu menumbuhkan mental positif dalam diri. Hal ini mampu menjadikan manusia tersebut menjadi pribadi yang lebih baik.

\section{Kepustakaan}

Astita, I. K. (1998). Wewidon Pupuh Kekendangan Dalam Karawitan Bali. Denpasar: Sekolah Tinggi Seni Indonesia.

Atmojo, B. S. (2010). Kendhangan Pamijen Gending Gaya Yogyakarta. Resital: Jurnal Seni Pertunjukan, 11(1), 45-58.

Bandem, I. M. (1983). Ensiklopedia Tari. Denpasar: ASTI.

Bandem, I. M. (2013). Gamelan Bali Diatas Panggung Sejarah. BP. STIKOM Bali.

Basrowi dan Suwandi. (2008). Memahami Penelitian Kualitatif. Jakarta: PT. Rineka Cipta.

Daryana \& Murwaningrum. (2019). Transformasi Musik Arumba: Wujud Hibriditas yang Mengglobal. Panggung, 29(1), 57-71.

Ediwar, Minawati, Yulika, H. (2019). Kajian

Organologi Pembuatan Alat Musik Saluang Darek Berbasis Teknologi Tradisional. Panggung, 29(2), 117-130.

I Putu Surya Pratama Wardhana, I Gede Mahendra Darma Wiguna, I. M. G. S. (2015). Pengembangan Aplikasi Instrumen Gamelan Gong Kebyar Berbasis Android. Nasional Pendidikan Teknik Informatika, 4(2), 58-66.
Mulyana, D. (2010). Ilmu Komunikasi: Suatu Pengantar. Bandung: Remaja Rosdakarya.

Pryatna, I. P. D. (2019). Metode Mengajar Kendang Tunggal I Ketut Widianta. Kajian Seni, 6(1), 25-37.

Putu Paristha Prakasih, Hendra Santosa, I. G. Y. (2018). Tirtha Campuhan: Karya Komposisi Baru dengan Media Gamelan Semar Pagulingan. Resital: Jurnal Seni Pertunjukan, 19(3), 113-121. https://doi.org/ttps://doi. org/10.24821/resital.v19i3.2452

Sadguna, I Gde Made Indra. (2019). Komunikasi Musikal Dalam Seni Pertunjukan Bali: Studi Kasus Tari Barong Ket. Segara Widya, 7(2), 104-116.

Sadguna, I Gede Made Indra. (2010). Kendang Bebarongan Dalam Karawitan Bali Sebuah Kajian Organologi. Yogyakarta: Kanisius (Anggota IKAPI).

Saepudin, A. (2015). Laras, Surupan, dan Patet dalam Praktik Menabuh Gamelan Salendro. Resital: Jurnal Seni Pertunjukan, 16(1), 52-64. Santosa, Hendra. Nina Herlina Lubis., Kunto Sofianto, R. M. (2017). Seni Pertunjukan Bali pada Masa Dinasti Warmadewa. MUDRA Jurnal Seni Budaya, 32(1), 81-91.

Santosa. (2008). Menggagas Komunikasi Musikal dalam Pertunjukan Gamelan. Ilmu Komunikasi, 5(2), 65-80.

Santosa, H. (2017). Gamelan Perang di Bali Abad ke-10 Sampai Awal Abad ke-21. Sumedang: Universitas Padjadjaran.

Supanggah, R. (2009). Bhoteka Karawitan II: Garap. Surakarta: ISI Press.

Suweca, I. W. (2005). Dasar Kekendangan Gupekan Nunggal dalam Gamelan Bali. Bheri, 4(1), 1-19.

Tenzer, M. (1998). Balinese Music. Periplus Edition, (HK) Ltd.

Yasa, I. K. (2018). Angsel-Angsel dalam Gong Kebyar. MUDRA Jurnal Seni Budaya, 33(1), 85-92.

\section{Informan}

I Kadek Suryantara Asmara Putra (24 tahun). Seniman, tinggal di Jalan Salya Gang 4e 
no.24, Denpasar Utara. HP.: $082147609847 . \quad$ I Made Rianta (25 tahun). Guru SMK, tinggal di I Ketut Suarjana (47 tahun). Seniman, tinggal Jalan Teleng Gang IV No.2 Kesiman Petilan, di Jalan Seroja, Gang Buni no.3. HP.: Denpasar Timur. HP.: 085333675962. 081805425596. 